\title{
PENGARUH SIKAP UNTUK KELUAR DARI KEMISKINAN TERHADAP KEBERDAYAAN MASYARAKAT MISKIN
}

\author{
Maimun Sholeh \\ Universitas Negeri Yogyakarta \\ maimunsholeh@uny.ac.id
}

\begin{abstract}
Abstrak: Penelitian ini bertujuan untuk mengetahui pengaruh sikap masyarakat miskin untuk keluar dari kemiskinan terhadap keberdayaan masyarakat miskin khususnya masyarakat miskin yang diberdayakan oleh lembaga zakat sehingga bisa dibuat strategi yang tepat untuk meningkatkan keberdayaan mereka. Penelitian ini merupakan studi eksplanatori dilakukan dengan menggunakan pendekatan SEM (Structural Equation Model). Anggota sampel ditentukan dengan metode non-probability sampling khususnya dengan purposive sampling. Data dikumpulkan secara cross section dianalisis secara kuantitatif. Dalam penelitian ini dapat disimpulkan bahwa sikap untuk keluar dari kemiskinan berpengaruh positif dan signifikan terhadap keberdayaan.
\end{abstract}

Kata kunci: Keberdayaan Masyarakat Miskin, Sikap

\section{THE INFLUENCE OF ATTITUDE TO EXIT FROM POVERTY ON THE POWER OF THE POOR COMMUNITY}

\begin{abstract}
This study aims to decide the effect of the attitude of the poor to get out of poverty on the empowerment of the poor, especially the poor who are empowered by zakat institutions so that proper strategies can be made to increase their empowerment. This research is an explanatory study conducted using the SEM (Structural Equation Model) approach. The sample members are determined by the non-probability sampling method especially with purposive sampling. Data collected by cross-section were analyzed quantitatively. In this study it can be concluded that the attitude to get out of poverty has a positive and significant effect on empowerment.
\end{abstract}

Keywords: Poor Community Empowerment, Attitude

\section{PENDAHULUAN}

Kemiskinan bukanlah sesuatu yang berdiri sendiri, tetapi terwujud sebagai hasil interaksi ketidakberdayaan antara berbagai aspek yang ada dalam kehidupan manusia, terutama aspek sosial dan aspek ekonomi maupun aspek perilaku. Tipologi kemiskinan juga dicirikan oleh berbagai dimensi, baik dimensi sosial maupun ekonomi sehingga pola kemiskinan juga berbedabeda. Menurut Max-Neef (1992), terdapat enam macam kemiskinan yang ditanggung komunitas dan membentuk suatu pola kemiskinan tertentu, yaitu (a) kemiskinan subsistensi; penghasilan rendah, jam kerja panjang, perumahan buruk, fasilitas air bersih mahal; (b) kemiskinan perlindungan; lingkungan buruk (sanitasi, sarana pembuangan sampah, polusi), kondisi kerja buruk, tidak ada jaminan atas hak pemilikan tanah; (c) kemiskinan pemahaman; kualitas pendidikan formal buruk, terbatasnya akses atas informasi yang menyebabkan terbatasnya kesadaran atas hak, kemampuan dan potensi untuk mengupayakan perubahan, (d) kemiskinan partisipasi; tidak ada akses dan kontrol atas proses pengambilan keputusan yang menyangkut nasib diri dan komunitas; (e) kemiskinan identitas; terbatasnya pembauran antar kelompok sosial, terfragmentasi; dan (f) kemiskinan kebebasan; stres, rasa tidak berdaya, tidak aman baik di tingkat pribadi maupun komunitas.

Khusus Indonesia, secara umum, angka gini rasio dan angka kemiskinan masih tinggi. Secara umum angka gini rasio pada periode 1996-2018 di Indonesia berfluktuasi. Fluktuasi angka Gini Rasio mengindikasikan adanya perubahan distribusi pengeluaran penduduk. Pada periode 
1996-1999 terjadi perbaikan distribusi pengeluaran penduduk sedangkan pada periode 1999-2007 justru distribusi pengeluaran penduduk di Indonesia semakin buruk. . Angka kemiskinan sejak 1970 - 2018 masih relative tinggi walaupun cenderung terus menurun (BPS, 2017).

Menurut Novida (2006), kemiskinan disebabkan oleh faktor internal, eksternal, nilai budaya yang kurang mendukung, dan kurangnya akses terhadap pemanfaatan pembangunan. Rendahnya akses terhadap pembangunan berhubungan dengan modal dasar yang dimiliki masyarakat miskin seperti rendahnya pendidikan, banyaknya jumlah anggota keluarga yang harus ditanggung dan rendahnya kepemilikan aset serta rendahnya motivasi untuk keluar dari kemiskinan. Agar mampu keluar dari kemiskinan dibutuhkan adanya perubahan motivasi serta perilaku, karena tidak adanya motivasi dan perilaku menerima keadaan (pasrah) merupakan cermin dari keluarga miskin. Menurut Lewis (1988), untuk menanggulangi kemiskinan, maka pemberdayaan serta perbaikan dan perubahan struktur kemasyarakatan orang miskin perlu mendapat perhatian karena orang miskin biasanya berperilaku malas, fatalisme, rendah diri, dan kurang menghormati etos kerja. Prinsip dari pemberdayaan masyarakat adalah memberikan landasan tersedianya akses ekonomi bagi orang miskin dan pemanfaatan potensi serta sumberdaya yang dimiliki masyarakat miskin secara optimal agar masyarakat miskin berdaya, memiliki keberdayaan.(Adimiharja, 2001).

Suatu masyarakat dikatakan berdaya jika masyarakat yang awalnya tidak mampu memenuhi kebutuhan hidupnya secara bermartabat atau tidak mempunyai gagasan menjadi masyarakat yang mampu memenuhi tidak hanya kebutuhan kebutuhan pokok tetapi juga mampu melakukan alternatif pilihan gagasan atau tindakan agar terwujudnya keinginan yang diharapkan. Keberdayaan meliputi keberdayaan berpikir, bertindak dan mengendalikan apa yang mereka lakukan. Keberdayaan masyarakat merupakan suatu kondisi yang dialami oleh masyarakat yang ditandai dengan kemampuan memikirkan, memutuskan serta melakukan sesuatu yang dipandang tepat demi mencapai pemecahan masalah-masalah yang dihadapi dengan mempergunakan daya/kemampuan yang dimiliki. Daya kemampuan yang dimaksud adalah kemampuan kognitif, konatif, psikomotorik, dan afektif serta sumber daya lainnya yang bersifat fisik/material. Dasmin Sidu (2007) dalam studinya menyimpulkan bahwa modal fisik, modal manusia, dan modal sosial berperan secara signifikan dalam menciptakan keberdayaan. Menurut Dasmin Sidu tingkat keberdayaan masyarakat memiliki korelasi positif dan cukup kuat dengan ketersediaan faktor modal fisik (physical capital), modal manusia (human capital), modal sosial (social capital), perubahan sikap, dan perubahan perilaku. Perubahan perilaku merupakan upaya singkat untuk meningkatkan keberdayaan masyarakat miskin.

Karena pondasi utama pemberdayaan masyarakat miskin yang terkait dengan modal dasar yang dimiliki masyarakat miskin serta sikap dan perilaku mereka, maka upaya pemberdayaan masyarakat dapat pula dilakukan dengan berbasis Zakat, dimana Strategi demikian menurut Sri Edi Swasono (2010) disebut Strategi Societal Welfare. Semua itu sesuai dengan pensyari'atan zakat yang memiliki fungsi mewujudkan keadilan sosial. Pendekatan pemberdayaan masyarakat berbasis zakat bertujuan untuk menginternalisasikan tujuan zakat bagi perubahan kesejahteraan masyarakat miskin (duafa). Zakat bukan hanya ibadah maliyah yang hanya karitatif, melainkan juga digunakan untuk mendorong terwujudnya perubahan kesejahteraan masyarakat duafa sehingga memiliki daya untuk berusaha dan mandiri sehingga dapat meningkatkan pendapatan agar terjadi peningkatan kesejahteraan secara materi maupun immateri sehingga mereka memiliki kepercayaan sehingga dapat mandiri serta menghindari sifat ketergantungan. (Yusuf Alqardawi, $1414 \mathrm{~h})$ 
Konsep zakat sebagai sumber keberdayaan atau kemandirian sangat sejalan dengan teori pembangunan berbasis partisipasi masyarakat. Zakat diatur untuk membangun keadilan sosialekonomi dan pembagian yang adil atas kekayaan dalam masyarakat. Dengan demikian maka posisi masyarakat miskin atau masyarakat yang terpinggirkan merupakan sasaran yang paling tepat bagi pemanfaatan dana zakat, sasaran pemberdayaan masyarakat berbasis zakat.

Konseptual keberdayaan masyarakat berbasis zakat disamping belum mendapat perhatian utama di beberapa lembaga zakat, dalam survey awal peneliti terhadap beberapa penerima manfaat zakat menunjukkan bahwa masih banyak perilaku masyarakat penerima manfaat zakat yang notabenenya adalah masyarakat miskin- yang enggan untuk segera keluar dari kemiskinan, perilaku lebih banyak meluangkan waktunya untuk kegiatan- kegiatan tidak produktif seperti mengemis atau kuli kasar. Masih banyak pandangan mustahiq yang menyatakan kondisi terjadi sekarang ini harus diterima sebagai takdir, atau alasan lingkungan alam yang tidak mendukung sehingga terjadi kemiskinan, atau pemerintah yang bertanggung jawab atas terjadinya kemiskinan ini.

Oleh karena itu penelitian tentang keberdayaan masyarakat miskin berbasis zakat yang dihubungkan dengan perilaku masyarakat miskin menarik untuk dilaksanakan karena dengan penelitian ini akan dapat diketahui apakah pemberdayaan dengan model berbasis zakat efektif atau tidak dalam merubah perilaku dan keberdayaan mereka, juga akan diketahui apa saja determinan utama keberdayaan masyarakat miskin dan dengan diketahuinya determinan utama keberdayaan masyarakat miskin maka bisa dibuat strategi pemberdayaan yang tepat. Yogyakarta di pilih sebagai tempat penelitian karena masyarakat Yogyakarta sangat rasional juga sangat plural. Masyarakat Yogyakarta sangat berpendidikan dan berbudaya serta toleran baik dalam relasi intra maupun inter-religi namun masyarakat miskinnya juga sangat banyak. Sementara sampel penelitian diambil dari Mustahiq penerima zakat LAZ Dhompet Dhuafa Yogyakarta

\section{METODE}

Jenis penelitian ini adalah penelitian deskriptif kuantitatif. Penelitian ini menggunakan data primer yang bersumber pada kuesioner dan wawancara terstruktur terhadap responden dengan menggunakan daftar pertanyaan yang telah dipersiapkan sebelumnya, dimana mustahiq penerima manfaat pemberdayaan sebagai anggota sampel. Anggota sampel ditentukan dengan metode nonprobability sampling khususnya dengan purposive sampling. Sampel diambil secara purposive dengan menggunakan metode Slovin dengan tingkat kekeliruan pengambilan sampel yang ditolerir sebesar $10 \%$.

Dalam studi ini yang menjadi obyek penelitian adalah kemiskinan dalam hubungannya dengan pemberdayaan dan perilaku serta keberdayaannya. Sementara itu, yang menjadi subyek penelitian adalah mustahiq yang ada di wilayah yogyakarta dan yang mendapat pemberdayaan dari Lembaga Amil Zakat. Analisis data dalam penelitian ini adalah Structural Equation Modeling (SEM). SEM digunakan dalam penelitian ini karena SEM dapat menjawab pertanyaan penelitian yang bersifal regresif maupun dimensional.

Model pengukuran faktor sikap untuk keluar dari kemiskinan mengacu pada tulisan Fujikake (2008); dibentuk melalui 5( lima) indicator yaitu keyakinan kondisi yang sedang dihadapi dapat dirubah, Kemiskinan bukan takdir, Tidak senang terhadap kemiskinan, Senang bisa keluar dr kemiskinan, Niat yang kuat untuk keluar dari kemiskinan.

$\mathrm{Y} 11=\lambda 1.1 \eta 1+\varepsilon 11$

$\mathrm{Y} 12=\lambda 1.2 \eta 1+\varepsilon 12$ 
$\mathrm{Y} 13=\lambda 1.3 \eta 1+\varepsilon 13$

$\mathrm{Y} 14=\lambda 1.4 \eta 1+\varepsilon 14$

$\mathrm{Y} 15=\lambda 1.5 \eta 1+\varepsilon 15$

Keterangan :

$\eta 1=$ Sikap

$\lambda=$ Hubungan antara variable laten terhadap indicator

Y11 = Keyakinan kondisi yang sedang dihadapi dapat dirubah

Y12 = Kemiskinan bukan takdir

Y13 = Tidak senang terhadap kemisinan

Y14 = Niat yang kuat untuk keluar dari kemiskinan

Y15 = Bersedia untuk keluar dari kemiskinan

$\varepsilon \quad=$ Kesalahan pengukuran (measurement error).

Model pengukuran faktor keberdayaan mengacu pada hasil penelitian Rachel (2003), dan Marhaeni (2011) dibentuk melalui 5 (lima) indikator. Peningkatan pengetahuan, peningkatan aksesibilitas, peningkatan partisipasi, peningkatan keragaman dan kualitas produk yang dibeli, peningkatan aset. Model pengukuran variabel keberdayaan di atas dapat dikonversi menjadi persamaan berikut:

$\begin{aligned} \mathrm{Y} 11 & =\lambda 2.1 \eta 2+\varepsilon 21 \\ \mathrm{Y} 12 & =\lambda 2.2 \eta 2+\varepsilon 22 \\ \mathrm{Y} 13 & =\lambda 2.3 \eta 2+\varepsilon 23 \\ \mathrm{Y} 14 & =\lambda 2.4 \eta 2+\varepsilon 24 \\ \mathrm{Y} 15 & =\lambda 2.5 \eta 2+\varepsilon 25\end{aligned}$

Keterangan :

$\eta 2=$ Keberdayaan

$\lambda=$ Hubungan antara variable laten terhadap indicator

Y11 = Peningkatan pengetahuan/keterampilan

Y12 $=$ Peningkatan aksesibilitas

Y13 = Peningkatan partisipasi

Y14 $=$ Peningkatan keragaman dan kualitas produk yang dibeli

Y15 = Peningkatan aset

$\varepsilon \quad=$ Kesalahan pengukuran (measurement error).

Persamaan struktural (structural equations) dalam penelitian ini -yang dirumuskan untuk menyatakan hubungan kausalitas antar berbagai konstruk- dibangun dengan pedoman berikut ini.

$\mathrm{Y} 1=\beta 1 \mathrm{X} 1+\mathrm{z} 1$

Keterangan:

$\mathrm{X} 1$ = Pemberdayaan

$\mathrm{Y} 1=$ Sikap untuk keluar dari kemiskinan

$\mathrm{Z}=$ Kesalahan struktural (Structural error)

\section{HASIL DAN PEMBAHASAN}

Perilaku manusia atau sikap manusia disebabkan oleh banyak faktor, salah satunya adalah motivasi terhadap objek perilaku itu. Seseorang melakukan tindakan atau perilaku tertentu sangat 
ditentukan oleh apakah objek perilaku itu menyenangkan atau tidak. Dengan kata lain seseorang melakukan tindakan atau perilaku tertentu sangat ditentukan oleh apakah ia memiliki motivasi positif atau negatif terhadap objek perilaku itu.

Seseorang akan relatif lebih mudah dikondisikan untuk keluar dari kemiskinan apabila: (1) memiliki keyakinan -yang diperoleh dari pengetahuan dan pengalaman langsung- bahwa kemiskinan merupakan suatu kondisi yang bisa diubah dan bukan merupakan suatu takdir; (2) memiliki perasaan tidak senang terhadap kondisi kemiskinan dan (3) memiliki niat yang kuat untuk bisa keluar dari kondisi kemiskinan dan bersedia keluar dari kemiskinan.(Fujiayake, 2008). Dari kondisi-kondisi seseorang tersebut, dapat ditarik indikator sikap untuk keluar dari kemiskinan sebagai berikut: 1) Keyakinan bahwa kondisi kemiskinan yang dihadapi bisa diubah, 2) Keyakinan bahwa kemiskinan bukan merupakan suatu takdir, 3) Perasaan tidak senang terhadap kondisi kemiskinan yang dihadapi, 4) Perasaan senang untuk bisa keluar dari kondisi kemiskinan, 5) Niat yang kuat untuk bisa keluar dari kondisi kemiskinan, dan 6) Bersedia untuk keluar dari kondisi kemiskinan.

\begin{tabular}{lcc}
\multicolumn{3}{c}{ Tabel 1 Hasil Penilain (Skor) Terhadap Kualitas Sikap Responden } \\
\hline \multicolumn{1}{c}{ Variabel dan indicator } & Skor & Tingkat Penilaian \\
\hline $\begin{array}{l}\text { Sikap }(\mathbf{X}) \\
\quad \text { Keyakinan kondisi yang sedang }\end{array}$ & $\mathbf{3 . 2 0 1 3}$ & Cukup Tinggi \\
$\begin{array}{l}\text { dihadapi dapat dirubah } \\
\text { Kemiskinan bukan takdir }\end{array}$ & 3.1467 & Cukup Tinggi \\
$\begin{array}{l}\text { Tidak senang terhadap kemisinan } \\
\text { Senang bisa keluar dr kemiskinan }\end{array}$ & 3.5000 & Cukup Tinggi \\
$\begin{array}{l}\text { Niat yang kuat untuk keluar dari } \\
\text { kemiskinan }\end{array}$ & 3.4667 & Cukup Tinggi \\
\hline
\end{tabular}

Pemberdayaan sebagai proses menunjuk pada serangkaian tindakan yang dilakukan secara sistematis dan mencerminkan pentahapan kegiatan atau upaya mengubah masyarakat yang kurang atau belum berdaya, berkekuatan, dan berkemampuan menuju keberdayaan. Makna memperoleh daya, kekuatan atau kemampuan menunjuk pada sumber inisiatif dalam rangka mendapatkan atau meningkatkan daya, kekuatan atau kemampuan sehingga memiliki keberdayaan. Untuk bisa berdaya akan sangat tergantung dari obyek pemberdayaan itu sendiri, oleh karena itu masyarakat miskin hendaknya menyadari untuk keluar dari benang kusut kemiskinan perlu memperoleh daya atau kemampuan sebagai stimuli. Upaya pemecahan dengan mengoptimalkan sumberdaya yang dimiliki diharapkan mampu menciptakan nilai-nilai yang diharapkan masyarakat miskin untuk bisa keluar dari kemiskinan, tercermin dengan meningkatnya harkat dan martabat hidup.

Pencapaian tujuan pemberdayaan dapat diwujudkan dalam keberdayaan. Suatu masyarakat dikatakan berdaya jika masyarakat yang awalnya tidak mampu memenuhi kebutuhan hidupnya secara bermartabat menjadi masyarakat yang mampu tidak hanya kebutuhan pokok juga mampu melakukan alternatif pilihan tindakan agar terwujudnya keinginan yang diharapkan. Sumarjo (1999) mengatakan ciri-ciri masyarakat berdaya yaitu: 1) Mampu memahami diri dan potensinya, mampu merencanakan (mengantisipasi kondisi perubahan ke depan), 2) Mampu mengarahkan dirinya sendiri, 3) Memiliki kekuatan untuk berunding. 
Memiliki bargaining power yang memadai dalam melakukan kerjasama yang saling menguntungkan.

Bertanggungjawab atas tindakannya. Keberdayaan tidak hanya mampu memenuhi kebutuhan pokok batiniah dan lahiriah tapi juga bertambahnya nilai kepemilikan, aksesibilitas serta keikutsertaan berpartisipasi dalam aktivitas kemasyarakatan. Hal ini sangat penting artinya bagi masyarakat miskin, karena meningkatnya kemampuan memberikan motivasi untuk terus meningkatkan sumberdayanya guna mewujudkan harapan yang dinginkan. Pemerintah sebagai lembaga yang berperan membantu masyarakat untuk meningkatkan kemampuan masyarakat menjadi masyarakat yang berdaya menjadi tumpuan harapan agar apa yang telah dicapai (berdaya) bisa berkesinambungan.

Implementasi dari pemberdayaan sering mendapat hambatan dalam pelaksanaannya, mengingat keanekragaman persepsi yang ada di masyarakat. Menurut Adi (2003) beberapa kendala yang dihadapi berasal dari:

Kepribadian individu; kestabilan (homeostatis), kebiasaan (habit), seleksi Ingatan dan Persepsi (selective perception and retention), ketergantungan (dependence), super-ego, yang terlalu kuat, cenderung membuat seseorang tidak mau menerima pembaharuan, dan rasa tak percaya diri (self- distrust).

Sistem sosial; kesepakatan terhadap norma tertentu (conformity tonorms), yang mengikat sebagian anggota masyarakat pada suatu komunitas tertentu, kesatuan dan kepaduan sistem dan budaya (systemic and cultural coherence), kelompok kepentingan (vested Interest), hal yang bersifat sakral (The Sacrosanct), dan penolakan terhadap Orang Luar (rejection of outsiders).

Keberhasilan pemberdayaan keluarga masyarakat miskin dapat dilihat dari keberdayaan mereka yang menyangkut kemampuan ekonomi, kemampuan mengakses manfaat kesejahteraan, dan kemampuan kultural dan politis. Dengan semakin meningkatnya kemampuan ekonomi memberikan kebebasan lebih luas bagi masyarakat miskin untuk mengekpresikan keinginan yang diharapkan. Keberdayaan masyarakat dapat tercermin dari kebebasan mobilitas yaitu: kemampuan untuk pergi ke luar rumah atau wilayah tinggalnya, kemampuan membeli komoditas kecil seperti membeli barang-barang kebutuhan rumah tangga sehari-hari dan kemampuan membeli komoditas besar atau kemampuan membeli barang-barang sekunder atau tersier, seperti almari pakaian, TV, radio, handphone, dan pakaian keluarga (Suhartono, 2009).

\section{SIMPULAN}

Sikap untuk keluar dari kemiskinan berpengaruh positif dan signifikan terhadap keberdayaan. Dengan kata lain kuat lemahnya Sikap untuk keluar dari kemiskinan menentukan kuat lemahnya keberdayaan oleh karena itu untuk meningkatan keberdayaan mustahiq maka diperlukan upaya meningkatkan kemampuan mustahiq dengan pemberdayaan yang berkesinambungan. Oleh karena itu diperlukan penelitian lanjutan terutama terkait dengan bagaimana model pemberdayaan teknis terbaik yang disesuaikan dengan kondisi sosial dan keberdayaan mustahiq yang telah diungkapkan dalam penelitian ini. 
Jurnal Ekonomi \& Pendidikan, 16(1), 2019

\section{DAFTAR PUSTAKA}

Abu Zahrah, Muhammad, Ushul Al-Fiqh. (Darul Fikri al-Araby, 1958)

Adi, Isbandi Rukminto, 2008, Intervensi komunitasPengembangan Masyarakat sebagai Upaya Pemberdayaan Masyarakat, Jakarta: Rajawali Pers

Al- Syatibi , al-Muwafaqat Fi Usul al-Syariah, (Beirut, Dar al-Ma'rifah, 1416 H/ 1996M Jld 2).

Aziz, U. 2006. Karakteristik Kemiskinan dan Pengaruhnya Terhadap Kondisi Kemiskinan di Sumatera Utara. Jurnal Kebijakan Ekonomi. Universitas Indonesia, Jakarta.

Cousins, J. Bradley, 2005, Will The Real Empowerment Evaluation Please Stand Up?: A Critical Friend Perspective, Empowerment Evaluation: Principles in Practice, New York: The Gulford Press

Cox, David. 2004." Outline of Presentation on Poverty Alleviation Programs in th Asia Pacific Region." Makalah disampaikan pada International Seminar on Curriculum Develompent for Social Work Education in Indonesia. Bandung: Sekolah Tinggi Kesejahteraan Sosial. 2 Maret 2004.

Dasmin Sidu , 2007, Empowerment of the Community Around the Area of Jompi Preserved Forest Muna Regency, Southeast Sulawesi, Jurnal Penyuluhan, Maret 2007, Vol. 3, No. 1

David C. Korten, 1988 "Kerangka Kerja Perencanaan Untuk Pembangunan Yang Berpusat-PadaRakyat", dalam David C. Korten dan Sjahrir, (eds.), Pembangunan Berdimensi Kerakyatan (Jakarta:Yayasan Obor Indonesia, )

Departemen Pekerjaan Umum, 2008b, Review Partisipatif: Modul Khusus Fasilitator (F24) Pelatihan Madya I

Dhana, I Nyoman, dkk. 2008: Strategi Penanggulangan Kemiskinan di Desa Tianyar Barat Kecamatan.

Efendi, Tadjuddin Noer. 1993. Sumber Daya Manusia, Peluang Kerja dan Kemiskinan. Yogyakarta: PT Tiara Wacana.

Erika Takidah, 2001, Analisis Pengaruh Kualitas Jasa Badan Amil Zakat Nasional Terhadap kepuasan Dan Kepecayaan Muzakki, Jakarta: Universitas Indonesia.

Ferdinand, A. 2002. Structural Equation Modeling dalam Penelitian Manajemen. Semarang: BP UNDIP

Fetterman, David and Wandersman, Abraham, 2007, Empowerment Evaluation: Yesterday, Today, and Tomorrow, American Journal of Evaluation 2007; 28; 179

Fontana, Andrea dan Frey, James H, 2009, Wawancara Seni Ilmu Pengetahuan, Handbook of Qualitative Research, Yogyakarta: Penerbit Pustaka Pelajar

Foy, Nancy, 1994, Empowering People at Work, London:Grower Publishing Company

Friedmann, John. 1987. Planning in The Public Domain: From Knowledge to Action. Oxford, UK: Princeton University.

Fujikake, Yoko, 2008, Qualitative Evaluation: Evaluating People's Empowerent, Japanese Journal of Evaluation Studies, Vol 8 No 2, 2008, pp 25 - 37, Japan Evaluation Society

Iqbal, Munawar, "Zakat, Moderation and Aggregate Consumption in An Islamic Economy". Dlm Monzer Khaf(ed) "Lesson in Islamic Economic, Vol.1. (Jeddah: Islamic Research and Training Institute,IDB, 1998)

Kahf, Monzer (1976). A Contribution to the Theory of Consumer Behaviour in an Islamic Society. Paper presented at The First International Conference on Islamic Economics, Jeddah, February 1976.

Kesi Widjajanti, 2011, Model Pemberdayaan Masyarakat, Jurnal Ekonomi Pembangunan Volume 12, Nomor 1, Juni 2011, Hlm.15-27 
M.Hamdar Arraiyyah, 2007, Meneropong Fenomena Kemiskinan Telaah Perspektif Al-Quran, Yogyakarta: Pustaka Pelajar

Marhaeni, A.A.I.N. "Tingkat Keberdayaan Perempuan Bali dalam Jabatan Eselon di Propvinsi Bali: Ditinjau dari Demensi Internal dan eksterna". Disertasi. Pasca Sarjana Universitas Gajah Mada. Yogyakarta. 2011

Rachel Mc.Cartney, Higher Risk Of Death In Rural Blacks And Whites Than Urbanites Is Related To Lower Incomes,Education, Mental Health Journal. Vol. 39, No. 2, April 2003. 